\title{
Stage 0 Eyelid Carcinoma AJCC v8
}

National Cancer Institute

\section{Source}

National Cancer Institute. Stage O Eyelid Carcinoma A/CC v8. NCI Thesaurus. Code C140515.

Stage 0 includes: T is, NO, MO. T is: Carcinoma in situ. NO: No evidence of lymph node involvement. M0: No distant metastasis. (AJCC 8th ed.) 